\title{
The Effects of Geometrical Scaling on the Frequency Response and Noise Performance of SiGe HBTs
}

\author{
Shiming Zhang, Student Member, IEEE, Guofu Niu, Member, IEEE, John D. Cressler, Fellow, IEEE, \\ Alvin J. Joseph, Member, IEEE, Greg Freeman, Member, IEEE, and David L. Harame, Senior Member, IEEE
}

\begin{abstract}
We examine the geometrical scaling issues in SiGe HBT technology. Width scaling, length scaling, and stripe-number scaling are quantified from a radio frequency (RF) design perspective at $2 \mathrm{GHz}$. We conclude that a SiGe HBT with emitter area $A_{E}=0.5 \times 20 \times 6 \mu^{2}$ is optimum for low noise applications at $J_{C}=0.1 \mathrm{~mA} / \mu \mathrm{m}^{2}$ and $f=2 \mathrm{GHz}$ using the design methodology, which guarantees optimal noise and input impedance matching with the simplest matching network. Finally, the optimal device sizes at $f=4,6 \mathrm{GHz}$ for low noise applications are also obtained using the same method.
\end{abstract}

Index Terms-Geometrical scaling, low noise amplifier (LNA), noise figure, noise model, SiGe HBT.

\section{INTRODUCTION}

W HILE vertical profile scaling of emerging SiGe HBT technologies has received significant recent attention, the design issues and tradeoffs associated with geometrical scaling of a given SiGe technology generation have not been explored in detail. This is particularly true with respect to radio frequency (RF) performance metrics, where an empirical approach to optimum device geometry is frequently adopted (i.e., measure a large matrix of device sizes to determine the best one). We attempt to shed light on these geometrical scaling issues in SiGe HBT technology by addressing the following question: Given a specific SiGe HBT technology generation (i.e., vertical doping and Ge profile fixed), what is the device geometry that best optimizes a given RF performance metric? In this work, we focus on the frequency response and broadband noise performance at the practical $\mathrm{RF}$ frequencies of 2, 4 and $6 \mathrm{GHz}$ and which would be required in the development of a low noise amplifier (LNA), for instance. Our results are based on a commercial $0.5 \mu \mathrm{m} \mathrm{SiGe} \mathrm{HBT} \mathrm{technology} \mathrm{[1],} \mathrm{but} \mathrm{our}$ approach can be easily extended to any SiGe technology.

Manuscript received August 7, 2001; revised November 29, 2001. This work was supported by the Semiconductor Research Corporation under Contract 2000-HJ-769 and an IBM University Partner Award. The review of this paper was arranged by Editor J. N. Burghartz.

S. Zhang, G. Niu, and J. D. Cressler are with the Electrical and Computer Engineering Department, Alabama Microelectronics Science and Technology Center, Auburn University, Auburn, AL 36849 USA (e-mail: zhangsh@eng.auburn.edu).

A. J. Joseph and D. L. Harame are with IBM Microelectronics, Essex Junction, VT 05452 USA.

G. Freeman is with IBM Microelectronics, Hopewell Junction, NY 12533 USA.

Publisher Item Identifier S 0018-9383(02)01563-0.

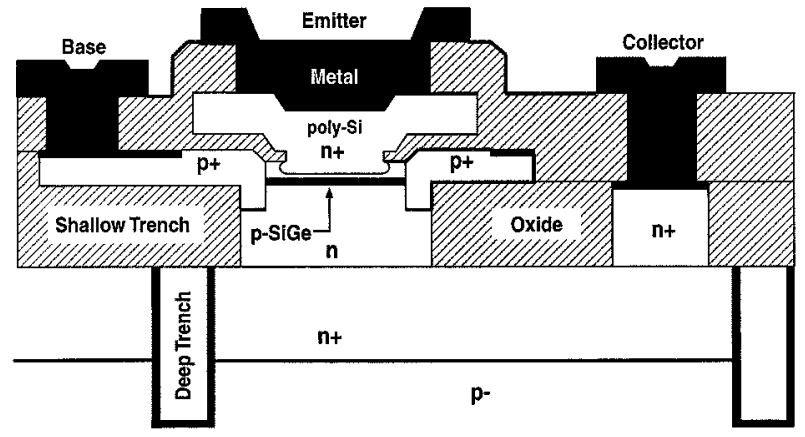

Fig. 1. Schematic cross-section of the UHV/CVD SiGe HBT.

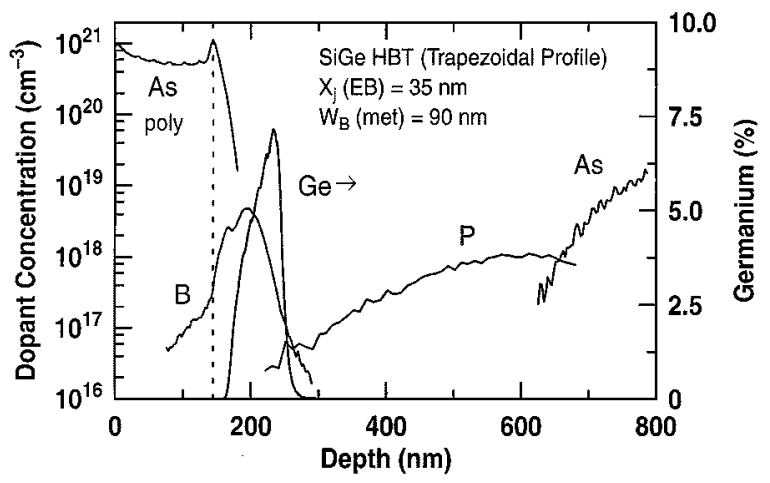

Fig. 2. Representative SIMS doping and Ge profiles of the UHV/CVD SiGe HBTs.

\section{DeVice Technology And PARAmeter EXTRACTION}

The SiGe HBT was fabricated using a self-aligned epitaxial-base technology [1]. It has a planar structure and deep trench/shallow trench isolation, as shown in Fig. 1. The SiGe base is deposited in an ultrahigh-vacuum/chemical vapor deposition (UHV/CVD) low temperature epitaxy (LTE) system. The intrinsic collector was formed by a double ion implantation to realize high performance. Representative vertical doping and Ge profiles of the SiGe HBT are shown in Fig. 2.

There are in general three geometrical variables associated with scaling: emitter stripe width $W$, emitter stripe length $L$, and the number of stripes $S$ of a given emitter stripe width and length. We present results on SiGe HBTs with: $A_{E}=0.3 \times$ $2.5 \mu \mathrm{m}^{2}, A_{E}=0.4 \times 2.5 \mu \mathrm{m}^{2}, A_{E}=0.6 \times 2.5 \mu \mathrm{m}^{2}$ (variable $W$ ), $A_{E}=0.5 \times 2.5 \mu \mathrm{m}^{2}, A_{E}=0.5 \times 5 \mu \mathrm{m}^{2}, A_{E}=$ $0.5 \times 20 \mu \mathrm{m}^{2}$ (variable $L$ ), $A_{E}=0.5 \times 20 \times 2 \mu \mathrm{m}^{2}, A_{E}=$ $0.5 \times 20 \times 4 \mu \mathrm{m}^{2}, A_{E}=0.5 \times 20 \times 8 \mu \mathrm{m}^{2}$ (variable $S$ ) and 50 $A_{E}=0.5 \times 2.5 \mu \mathrm{m}^{2}$ in parallel. These devices were measured 


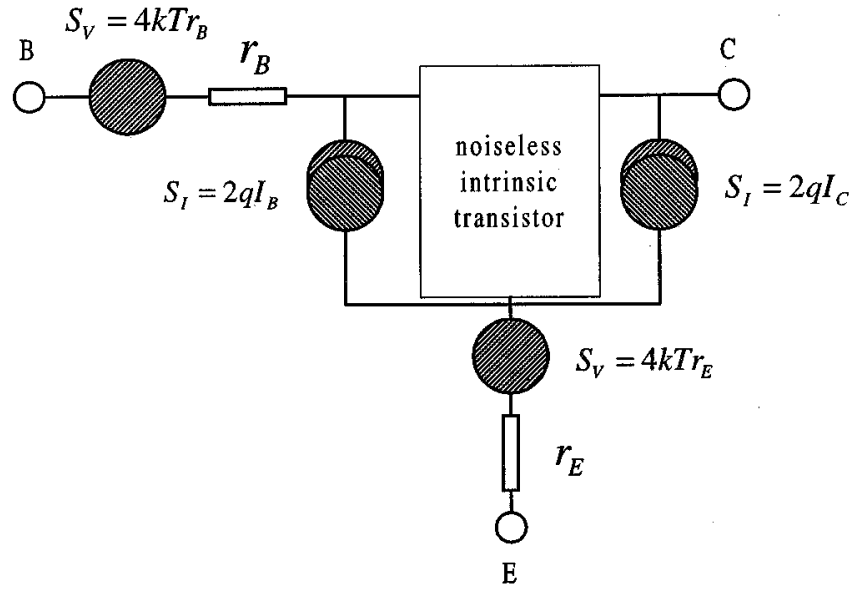

Fig. 3. Circuit schematic of the SPICE noise model.

at room temperature $(T=300 \mathrm{~K})$ using an HP4155 semiconductor parameter analyzer (dc) and an HP8510C vector network analyzer [scattering $(S)$ parameters]. The cutoff frequency $f_{T}$, the maximum oscillation frequency $f_{\max }$, and the total emitter and base resistance $r_{B E}$ of the devices were extracted from measured $S$-parameters, while the noise parameters (the minimum noise figure $\mathrm{NF}_{\min }$, the noise resistance $R_{n}$, and the optimum source reflection coefficient $\Gamma_{S, \text { opt }}$ ) and the associated available gain $G_{A, \text { assoc }}$ were obtained using the measured $S$-parameters and the appropriate noise model [2], [3].

\section{NOISE MODEL}

Direct measurement of noise figure in the $\mathrm{GHz}$ range requires substantial experimental effort. An alternative approach is to measure the transistor $S$-parameters, convert to $Y$-parameters, and calculate the noise figure through an appropriate noise model [3], which relates the $Y$-parameters to the noise figure. Such an approach has been demonstrated and its accuracy verified in the SiGe HBT technology under study [3]. This model is accurate at the ranges of collector current density $J_{C}=0.05-0.2 \mathrm{~mA} / \mu \mathrm{m}^{2}$ and frequency $f=2-10 \mathrm{GHz}$. At higher current densities (up to $1 \mathrm{~mA} / \mu \mathrm{m}^{2}$ ), this model can still be used for the relative comparison, meaning that this model can determine which device has better noise performance. Fig. 3 illustrates the circuit schematic used in deriving the noise model. The principal noise sources in this model are the base and collector shot noise $\left(2 q I_{B}, 2 q I_{C}\right)$, emitter thermal noise, and base thermal noise. At a given bias and frequency, the noise figure (NF) is a function of the source admittance. The minimum noise figure $\left(\mathrm{NF}_{\min }\right)$ occurs at the optimum source admittance $\left(Y_{S, \text { opt }}\right)$. The equations for the minimum noise figure $\left(\mathrm{NF}_{\min }\right)$ and the optimum source admittance $\left(Y_{S, \text { opt }}\right)$ can be found in [3]. In noise measurements, the source reflection coefficient $\left(\Gamma_{S, \text { opt }}\right)$ is often used instead of the admittance $Y_{S, o p t}$

$$
\Gamma_{S, o p t}=\frac{1-Y_{S, o p t} Z_{0}}{1+Y_{S, o p t} Z_{0}}
$$

where $Z_{0}$ is the characteristic impedance.
TABLE I

EFFECTS OF EMITTER WIDTH VARIATION

\begin{tabular}{cccc}
\hline $\mathrm{A}_{\mathrm{E}}=\mathrm{W} \times \mathrm{L}\left(\mu \mathrm{m}^{2}\right)$ & $0.3 \times 2.5$ & $0.4 \times 2.5$ & $0.6 \times 2.5$ \\
\hline$\beta @ \mathrm{~J}_{\mathrm{C}}=0.1 \mathrm{~mA} / \mu \mathrm{m}^{2}$ & 91 & 89 & 88 \\
Peak $\mathrm{f}_{\mathrm{T}}(\mathrm{GHz})$ & 43 & 46 & 50 \\
Peak $\mathrm{f}_{\max }(\mathrm{GHz})$ & 80 & 79 & 68 \\
$\tau_{\mathrm{ec}}(\mathrm{ps})$ & 3.14 & 2.88 & 2.84 \\
$\mathrm{C}_{\mathrm{j}, \mathrm{eb}}+\mathrm{C}_{\mathrm{j}, \mathrm{cb}}(\mathrm{fF})$ & 21 & 24 & 29 \\
$\left(\mathrm{C}_{\mathrm{j}, \mathrm{eb}}+\mathrm{C}_{\mathrm{j}, \mathrm{cb}}\right) / \mathrm{A}_{\mathrm{E}}\left(\mathrm{fF} / \mathrm{um}^{2}\right)$ & 28 & 24 & 19.3 \\
$\mathrm{r}_{\mathrm{BE}}(\Omega) @ \mathrm{~J}_{\mathrm{C}}=0.1 \mathrm{~mA} / \mu \mathrm{m}^{2}$ & 97 & 111 & 132 \\
\hline
\end{tabular}

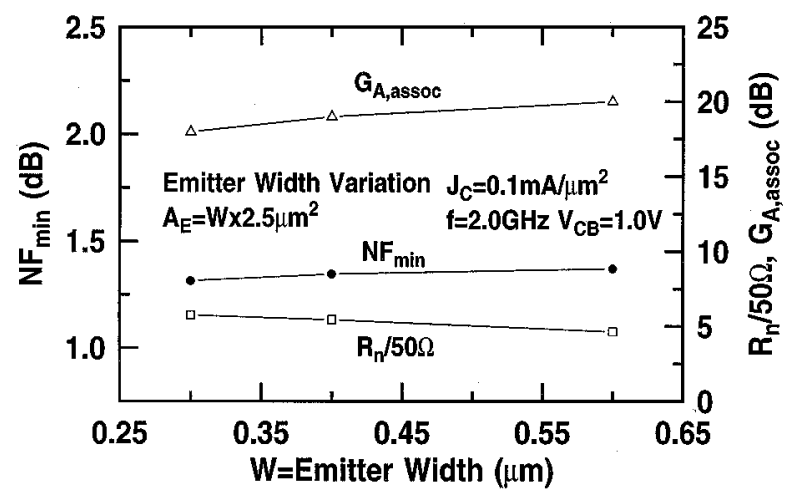

Fig. 4. Minimum noise figure $\mathrm{NF}_{\text {min }}$, normalized noise resistance $R_{n}$ (to 50 $\Omega$ ), and the associated available gain $G_{A, a s s o c}$ versus emitter width at $J_{C}=$ $0.1 \mathrm{~mA} / \mu \mathrm{m}^{2}$ and $f=2 \mathrm{GHz}$.

Another important parameter is the associated available gain $\left(G_{A, a s s o c}\right)$, which is derived by noise matching at the input and power matching at the output

$$
G_{A, a s s o c}=\left|\frac{Y_{21}}{Y_{11}+Y_{S, o p t}}\right|^{2} \frac{\operatorname{Re}\left(Y_{S, o p t}\right)}{\operatorname{Re}\left(Y_{22}-\frac{Y_{12} Y_{21}}{Y_{11}+Y_{S, o p t}}\right)} .
$$

\section{RESUlTS AND DISCUSSION}

\section{A. Emitter Width Variation}

The effects of emitter width variation are given in Table I. As emitter width decreases from 0.6 to $0.4 \mu \mathrm{m}$, the reduction of the base resistance leads to a considerable improvement in $f_{\max }$. However, as emitter width decreases from 0.4 to $0.3 \mu \mathrm{m}$, $f_{\max }$ is almost unchanged mainly due to nonlinear scaling of total base-emitter resistance $r_{B E}$ with emitter width, meaning as emitter width decreases, the intrinsic base resistance is no longer dominant in $r_{B E}$ and the extrinsic base resistance becomes more important. Fig. 4 illustrates the emitter width dependence of the noise parameters of SiGe HBTs at $f=2 \mathrm{GHz}$ and $J_{C}=0.1 \mathrm{~mA} / \mu \mathrm{m}^{2}$, the relevant collector current density for low noise applications. Although as the emitter width decreases, $\mathrm{NF}_{\text {min }}$ decreases slightly, both the noise resistance $\left(R_{n}\right)$ and the associated available gain $\left(G_{A, a s s o c}\right)$ are degraded slightly, which means that the smaller emitter width is not necessarily better at $f=2 \mathrm{GHz}$ and $J_{C}=0.1 \mathrm{~mA} / \mu \mathrm{m}^{2}$ for low noise applications. However, using constant power (constant collector current here) comparison (which is the case from design point of view), $\mathrm{NF}_{\min }$ does improve considerably (about $0.25 \mathrm{~dB}$ at $I_{C}=0.1 \mathrm{~mA}$ ) as emitter width decreases at $I_{C} \leq 0.2 \mathrm{~mA}$, 


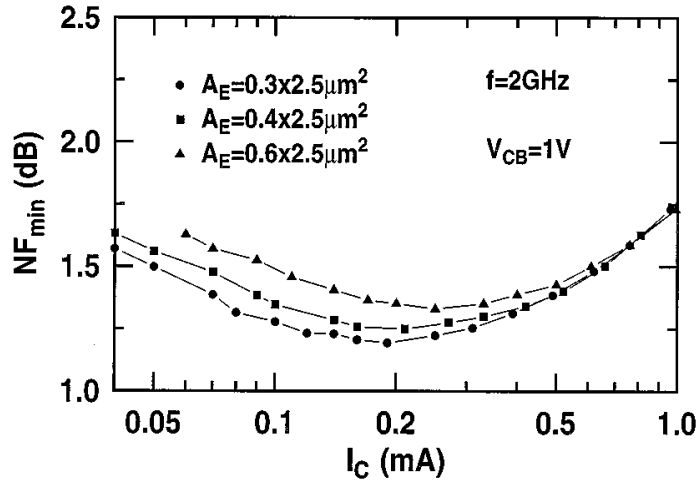

Fig. 5. Minimum noise figure $\mathrm{NF}_{\min }$ versus collector current $I_{C}$ for three devices with different emitter width at $f=2 \mathrm{GHz}$.

TABLE II

EFFECTS OF EMITTER LENGTH VARIATION

\begin{tabular}{|c|c|c|c|}
\hline$A_{E}=W \times L\left(\mu m^{2}\right)$ & $0.5 \times 2.5$ & $0.5 \times 5$ & $0.5 \times 20$ \\
\hline$\beta @ \mathrm{~J}_{\mathrm{C}}=0.1 \mathrm{~mA} / \mu \mathrm{m}^{2}$ & 106 & 100 & 96 \\
\hline (GHz) & 51 & 53 & 54 \\
\hline Peak $f_{n}$ & 66 & 64 & 64 \\
\hline$\tau_{\mathrm{ec}}$ & 2.68 & 2.64 & 2.63 \\
\hline $\mathrm{C}_{\mathrm{j}, \mathrm{eb}}+\mathrm{C}_{\mathrm{j}, \mathrm{cb}}(\mathrm{fF})$ & 20.2 & 40.1 & 148 \\
\hline$\left(\mathrm{C}_{\mathrm{j}, \mathrm{eb}}+\mathrm{C}_{\mathrm{j}, \mathrm{cb}}\right) / \mathrm{A}_{\mathrm{E}}(\mathrm{f} F / \mu \mathrm{n}$ & 16.16 & 16.04 & 14.8 \\
\hline $\mathrm{CBE}_{\mathrm{BE}}(\Omega) @ \mathrm{~J}_{\mathrm{C}}=0.1 \mathrm{~mA} / \mu \mathrm{m}^{2}$ & 130 & 72.3 & 22.5 \\
\hline
\end{tabular}

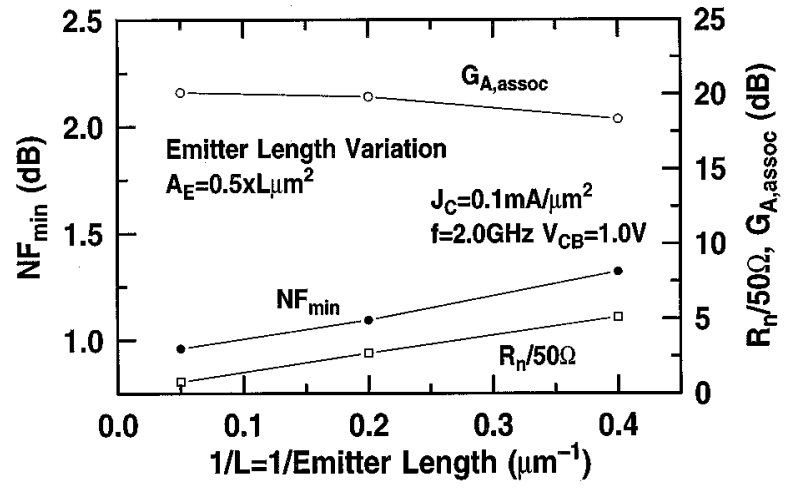

Fig. 6. Minimum noise figure $\mathrm{NF}_{\min }$, normalized noise resistance $R_{n}$ (to 50 $\Omega$ ), and the associated available gain $G_{A, a s s o c}$ versus reciprocal of emitter length at $J_{C}=0.1 \mathrm{~mA} / \mu \mathrm{m}^{2}$ and $f=2 \mathrm{GHz}$.

as shown in Fig. 5. Another way to understand Fig. 5 is to plot $\mathrm{NF}_{\text {min }}$ versus $J_{C}$ using the same data and it is not hard to image that as emitter width decreases, $\mathrm{NF}_{\min }$ are very close at $J_{C} \leq 0.2 \mathrm{~mA} / \mu \mathrm{m}^{2}$, but $\mathrm{NF}_{\min }$ decreases significantly at $J_{C} \geq 0.3 \mathrm{~mA} / \mu \mathrm{m}^{2}$. Therefore, smaller emitter width does improve $\mathrm{NF}_{\min }$ at higher current densities or using constant power comparison.

\section{B. Emitter Length Variation}

Table II compares typical transistor parameters for emitter length variations. As expected, the changes of $f_{T}$ and $f_{\max }$ are small as emitter length varies. Fig. 6 gives the emitter length dependence of the noise parameters of the SiGe HBTs at $J_{C}=$ $0.1 \mathrm{~mA} / \mu \mathrm{m}^{2}$ and $f=2 \mathrm{GHz}$. As emitter length increases from $2.5 \mu \mathrm{m}$ to $20 \mu \mathrm{m}, \mathrm{NF}_{\min }$ is reduced by a considerable amount $(0.3 \mathrm{~dB})$ and $R_{n}$ and $G_{A, a s s o c}$ are also improved. Therefore, a

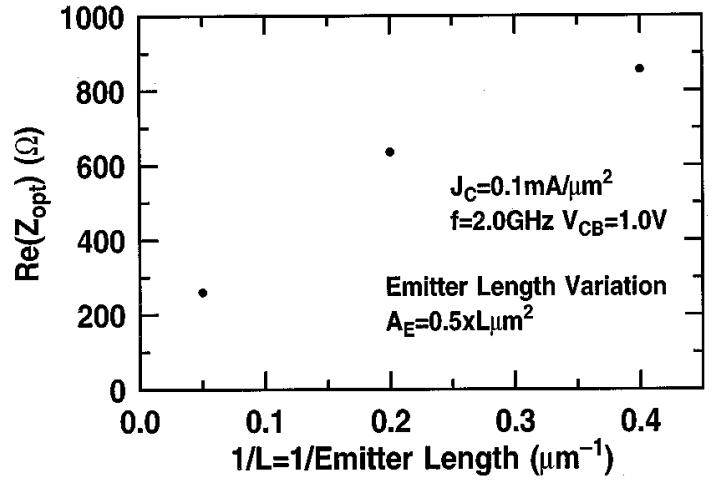

Fig. 7. Real part of the optimum source impedance as a function of reciprocal of emitter length at $J_{C}=0.1 \mathrm{~mA} / \mu \mathrm{m}^{2}$ and $f=2 \mathrm{GHz}$.

TABLE III

EFFECTS OF EMITTER STRIPE NUMBER VARIATION

\begin{tabular}{cccc}
\hline $\mathrm{A}_{\mathrm{E}}=\mathrm{W} \times \mathrm{L} \times \mathrm{S}\left(\mu \mathrm{m}^{2}\right)$ & $0.5 \times 20 \times 2$ & $0.5 \times 20 \times 4$ & $0.5 \times 20 \times 8$ \\
\hline$\beta @ \mathrm{~J}_{\mathrm{C}}=0.1 \mathrm{~mA} / \mu \mathrm{m}^{2}$ & 104 & 101 & 100 \\
$\mathrm{f}_{\mathrm{T}} @ \mathrm{~J}_{\mathrm{C}}=0.1 \mathrm{~mA} / \mu \mathrm{m}^{2}(\mathrm{GHz})$ & 23 & 22.8 & 22.5 \\
$\mathrm{f}_{\max } @ \mathrm{~J}_{\mathrm{C}}=0.1 \mathrm{~mA} / \mu \mathrm{m}^{2}(\mathrm{GHz})$ & 41 & 40.5 & 37.9 \\
$\tau_{\mathrm{ec}}(\mathrm{ps})$ & 2.7 & 2.8 & 2.9 \\
$\mathrm{C}_{\mathrm{j}, \mathrm{cb}}+\mathrm{C}_{\mathrm{j}, \mathrm{cb}}(\mathrm{fF})$ & 324 & 625 & 1336 \\
$\left(\mathrm{C}_{\mathrm{j}, \mathrm{eb}}+\mathrm{C}_{\mathrm{j}, \mathrm{cb}}\right) / \mathrm{A}_{\mathrm{E}}\left(\mathrm{fF} / \mu \mathrm{m}^{2}\right)$ & 16.2 & 15.6 & 16.7 \\
$\mathrm{r}_{\mathrm{BE}}(\Omega) @ \mathrm{~J}_{\mathrm{C}}=0.1 \mathrm{~mA} / \mathrm{m}^{2}$ & 11.4 & 6.1 & 3.8 \\
\hline
\end{tabular}

device with longer emitter length has better noise performance at $J_{C}=0.1 \mathrm{~mA} / \mu \mathrm{m}^{2}$ and $f=2 \mathrm{GHz}$ and thus it is preferred for LNA design. On the other hand, the real parts of the optimized source impedance $\operatorname{Re}\left(Z_{\text {opt }}\right)$ of these devices, as shown in Fig. 7, are well above $50 \Omega$. Since substrate and interconnect losses are significantly higher in Si than in GaAs, Si RF circuit designs should target the optimization of the size of the transistors in order to simplify matching, rather than design the matching circuit around a given transistor [2]. Therefore, in the design of an $\operatorname{SiLNA}, \operatorname{Re}\left(Z_{o p t}\right)$ of the transistor is usually chosen to be close to $50 \Omega$ so that the transistor becomes noise-matched to the characteristic impedance of the system, typically $50 \Omega$, at the desired frequency. Therefore, devices with multiple stripes are often needed for low noise applications.

\section{Emitter Stripe Number Variation}

Table III compares typical transistor parameters for emitter stripe number variations. For the device with $A_{E}=0.5 \times 20 \times$ $8 \mu \mathrm{m}^{2}, f_{\max }$ at $J_{C}=0.1 \mathrm{~mA} / \mu \mathrm{m}^{2}$ is slightly lower mainly due to nonlinear scaling of total base-emitter resistance $r_{B E}$ with the reciprocal of the stripe number $1 / \mathrm{S}$. Since other parameters such as $\beta, f_{T}, C_{j} / A_{E}$ and $\tau$ of the device with $A_{E}=0.5 \times 20 \times$ $8 \mu \mathrm{m}^{2}$ are either worse or comparable with those of other two devices with 2 and 4 stripe numbers, we expect that the device with 8 stripe number has worse noise performance than those of the devices with 2 and 4 stripe numbers.

Fig. 8 gives the emitter stripe number dependence of $\operatorname{Re}\left(Z_{\text {opt }}\right)$ at $J_{C}=0.1 \mathrm{~mA} / \mu \mathrm{m}^{2}$ and $f=2 \mathrm{GHz}$, from which the optimized device area $\left(A_{E}=0.5 \times 20 \times 6 \mu \mathrm{m}^{2}\right.$, referred to as device A) to match $50 \Omega$ is extracted. Basically, we can choose any unit cell as a building block $\left(A_{E}=0.5 \times 20 \mu \mathrm{m}^{2}\right.$ or $A_{E}=0.5 \times 2.5 \mu \mathrm{m}^{2}$ ) to get this optimized device area. 


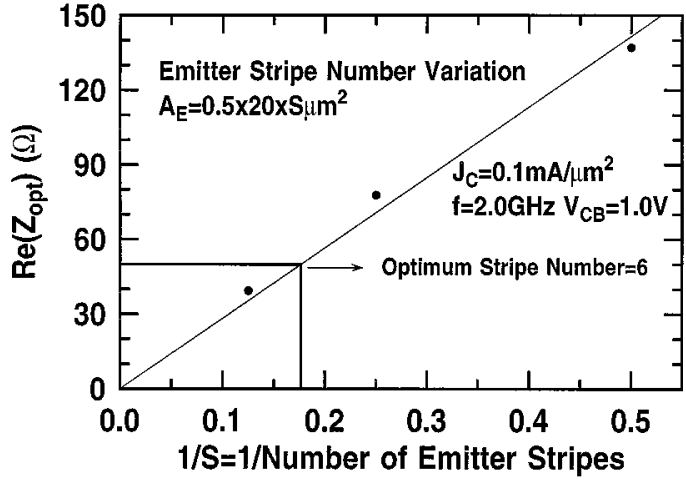

Fig. 8. Real part of the optimum source impedance as a function of reciprocal of emitter stripe number at $J_{C}=0.1 \mathrm{~mA} / \mu \mathrm{m}^{2}$ and $f=2 \mathrm{GHz}$.

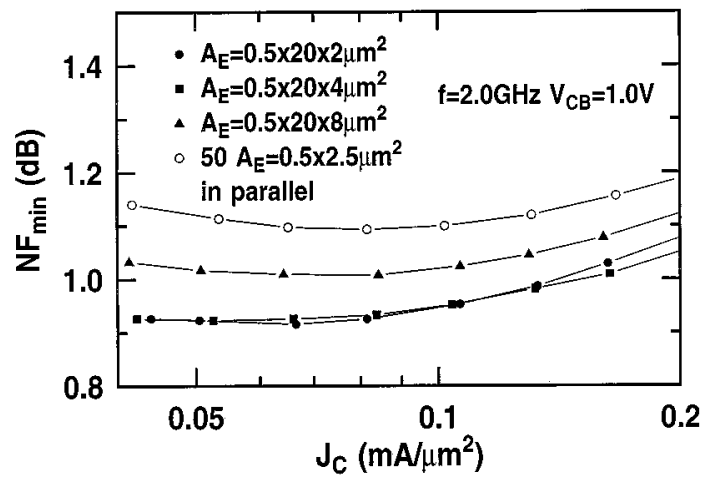

Fig. 9. Minimum noise figure versus collector current density for four different devices at $f=2 \mathrm{GHz}$.

$50 A_{E}=0.5 \times 2.5 \mu \mathrm{m}^{2}$ transistors in parallel (referred to as device B with $A_{E}=0.5 \times 2.5 \times 50 \mu \mathrm{m}^{2}$, which can be viewed as a device with $500.5 \times 2.5 \mu \mathrm{m}^{2}$ stripes), for instance, has a similar optimized device area and at $J_{C}=0.1 \mathrm{~mA} / \mu \mathrm{m}^{2}$ and $f=2 \mathrm{GHz}$ its $\operatorname{Re}\left(Z_{\text {opt }}\right)$ is $47.75 \Omega$, which is very close to 50 $\Omega$. Although both device A and device B can match $50 \Omega$ very well, the $\mathrm{NF}_{\min }$ of device $\mathrm{A}$ is at least $0.1 \mathrm{~dB}$ smaller than that of device B at $J_{C}=0.1 \mathrm{~mA} / \mu \mathrm{m}^{2}$ and $f=2 \mathrm{GHz}$, which can be seen in Fig. 9, which is consistent with the conclusion that longer emitter length is preferred for LNA design at $J_{C}=0.1 \mathrm{~mA} / \mu \mathrm{m}^{2}$ and $f=2 \mathrm{GHz}$.

To understand the differences in $\mathrm{NF}_{\text {min }}$ observed in Fig. 9, the contributions of the various noise sources need to be investigated. Any linear noisy two-port can be represented by its noiseless counterpart, an input current noise source $i_{n}$, an input voltage noise source $v_{n}$, and their correlation [4]. Basically, $\mathrm{NF}_{\min }$ is determined by $i_{n}$ and $v_{n}$ [5], and the smaller $i_{n}$ and $v_{n}$ are, the smaller $\mathrm{NF}_{\min }$ is. $i_{n}$ and $v_{n}$ are given by [5]

$$
\begin{aligned}
& \left\langle i_{n}^{2}\right\rangle=2 q I_{B}+\frac{2 q I_{C}}{\left|h_{21}\right|^{2}} \\
& \left\langle v_{n}^{2}\right\rangle=4 k T r_{B E}+\frac{2 q I_{C}}{\left|y_{21}\right|^{2}} .
\end{aligned}
$$

In order to compare devices with $A_{E}=0.5 \times 20 \times 2 \mu \mathrm{m}^{2}$, $A_{E}=0.5 \times 20 \times 4 \mu \mathrm{m}^{2}, A_{E}=0.5 \times 20 \times 8 \mu \mathrm{m}^{2}$ and device

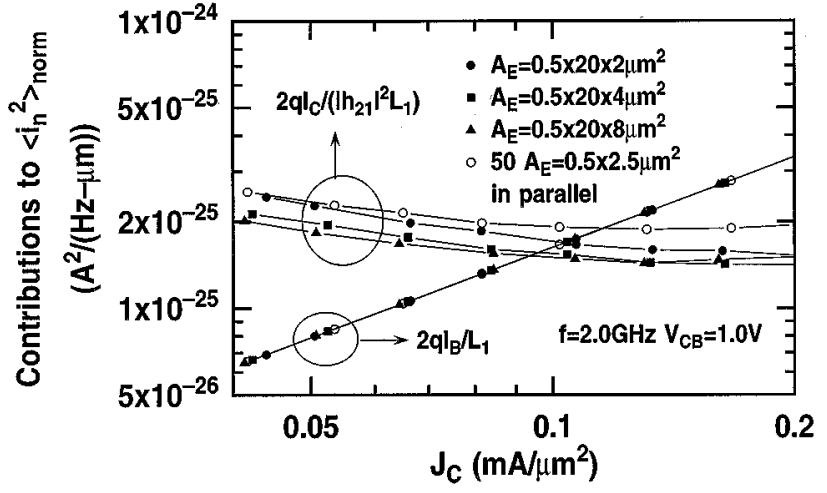

Fig. 10. $2 q I_{B} / L_{1}$ and $2 q I_{C} /\left(\left|h_{21}\right|^{2} L_{1}\right)$ contributions to $\left\langle i_{n 2}^{2}\right\rangle_{n o r m}$ versus collector current density at $f=2 \mathrm{GHz}$ for four different devices.

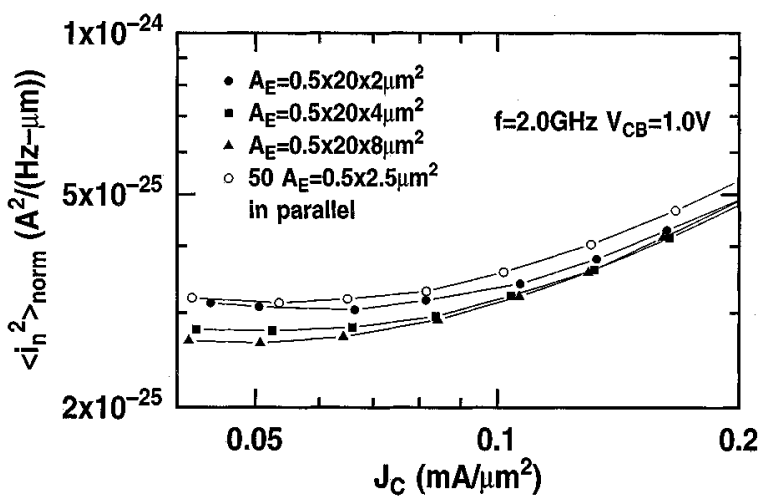

Fig. 11. $\left\langle i_{n}^{2}\right\rangle_{\text {norm }}$ versus collector current density at $f=2 \mathrm{GHz}$ for four different devices.

B with $A_{E}=0.5 \times 2.5 \times 50 \mu \mathrm{m}^{2},\left\langle i_{n}^{2}\right\rangle$ and $\left\langle v_{n}^{2}\right\rangle$ need to be normalized by the total emitter length $L_{1}$ of the device

$$
\begin{aligned}
\left\langle i_{n}^{2}\right\rangle_{\text {norm }} & \equiv \frac{\left\langle i_{n}^{2}\right\rangle}{L_{1}}=\frac{2 q I_{B}}{L_{1}}+\frac{2 q I_{C}}{\left|h_{21}\right|^{2} L_{1}} \\
\left\langle v_{n}^{2}\right\rangle_{\text {norm }} & \equiv\left\langle v_{n}^{2}\right\rangle \times L_{1}=4 K \operatorname{Tr}_{B E} L_{1}+\frac{2 q I_{C} L_{1}}{\left|y_{21}\right|^{2}}
\end{aligned}
$$

where $L_{1}$ is the product of the emitter length of a single emitter stripe and the emitter stripe number.

Fig. 10 compares the $2 q I_{B} / L_{1}$ and $2 q I_{C} /\left(\left|h_{21}\right|^{2} L_{1}\right)$ contributions to $\left\langle i_{n}^{2}\right\rangle_{\text {norm }}$ and Fig. 11 gives $\left\langle i_{n}^{2}\right\rangle_{\text {norm }}$ as a function of collector current density at $f=2 \mathrm{GHz}$ for these four different devices. Since the current gain in the RF bias region is similar for these four devices, the $2 q I_{B} / L_{1}$ contributions of these four devices are very close, while the $2 q I_{C} /\left(\left|h_{21}\right|^{2} L_{1}\right)$ contribution of device $\mathrm{B}$ is the largest among these four devices because of its smallest $\left|h_{21}\right|$. Therefore device $\mathrm{B}$ has the largest $\left\langle i_{n}^{2}\right\rangle_{\text {norm }}$ among these four devices.

Fig. 12 illustrates the $4 K \operatorname{Tr}_{B E} L_{1}$ and $2 q I_{C} L_{1} /\left|y_{21}\right|^{2}$ contributions to $\left\langle v_{n}^{2}\right\rangle_{\text {norm }}$ and Fig. 13 shows $\left\langle v_{n}^{2}\right\rangle_{\text {norm }}$ as a function of collector current density at $f=2 \mathrm{GHz}$ for these four different devices. The higher $\left\langle v_{n}^{2}\right\rangle_{\text {norm }}$ of device B and device with $A_{E}=0.5 \times 20 \times 8 \mu \mathrm{m}^{2}$ is mainly due to the larger $4 K \operatorname{Tr}_{B E} L_{1}$ contributions of these two devices, which lead to their larger $\mathrm{NF}_{\text {min }}$ (Fig. 9). As shown in Fig. 12, the $4 K \operatorname{Tr}_{B E} L_{1}$ contribution dominates $\left\langle v_{n}^{2}\right\rangle_{n o r m}$ across most of the bias current range, 


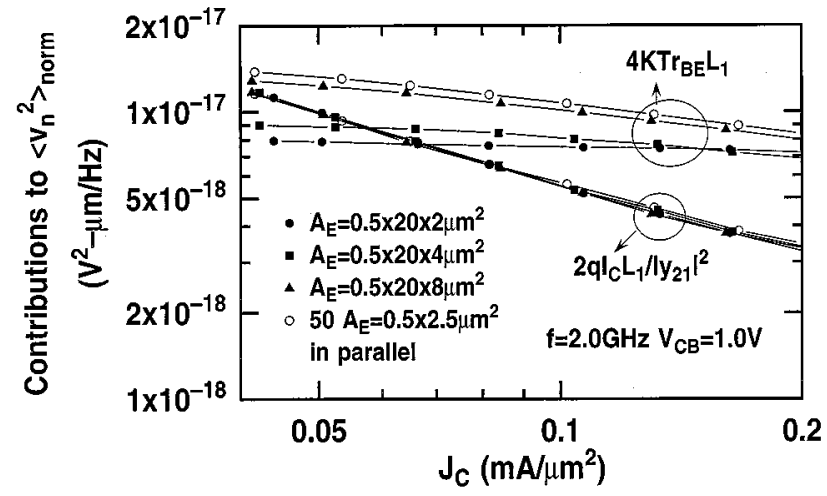

Fig. 12. $4 K \operatorname{Tr}_{B E} L_{1}$ and $2 q I_{C} L_{1} /\left|y_{21}\right|^{2}$ contributions for $\left\langle v_{\eta 2}^{2}\right\rangle_{\text {norm }}$ versus collector current density at $f=2 \mathrm{GHz}$ for four different devices.

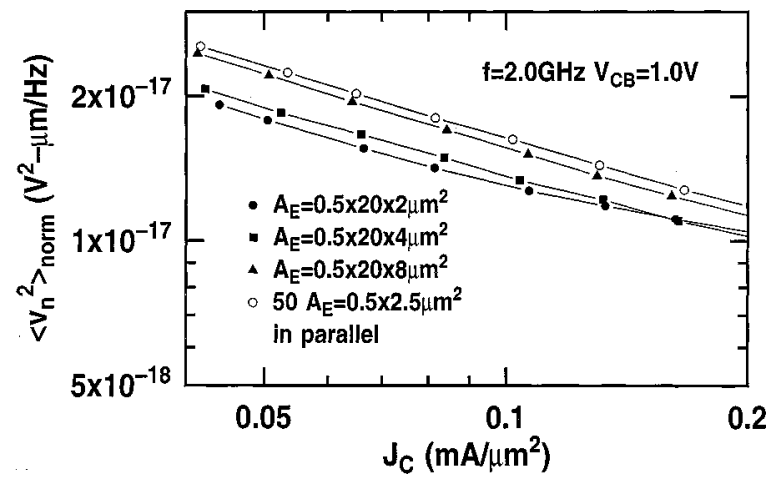

Fig. 13. $\left\langle v_{\eta \eta}^{2}\right\rangle_{\text {norm }}$ versus collector current density at $f=2 \mathrm{GHz}$ for four different devices.

indicating significant improvement of noise performance can be expected by increasing the base doping [5]. From this analysis, the higher $\mathrm{NF}_{\min }$ of device $\mathrm{B}$ is due to the larger $\left\langle i_{n}^{2}\right\rangle_{\text {norm }}$ and $\left\langle v_{n}^{2}\right\rangle_{\text {norm }}$ compared to those of the other three devices. Therefore, the current gain, the cutoff frequency and the total base and emitter resistance need to be improved to reduce the minimum noise figure.

For low noise applications, not only $\mathrm{NF}_{\min }$ is important, but also $\Delta f$, which is the difference between $\mathrm{NF}_{\min }$ and $\mathrm{NF}$ for 50 $\Omega$ source impedance and is given by [6]

$$
\Delta f=\frac{4 r_{n}\left|\Gamma_{S, o p t}\right|^{2}}{\left|1+\Gamma_{S, o p t}\right|^{2}}
$$

where $r_{n}=R_{n} / 50, \Gamma_{S, \text { opt }}$ is the optimum source reflection coefficient, and $R_{n}$ is the noise resistance.

Fig. 14 shows $\Delta f$ versus $J_{C}$ for the four different devices. We see that device $\mathrm{A}$ and device $\mathrm{B}$ have similar $\Delta f$ at $J_{C}=$ $0.1 \mathrm{~mA} / \mu \mathrm{m}^{2}$ and $f=2 \mathrm{GHz}$. Therefore, we conclude that a SiGe HBT with $A_{E}=0.5 \times 20 \times 6 \mu \mathrm{m}^{2}$ is the optimized device at $J_{C}=0.1 \mathrm{~mA} / \mu \mathrm{m}^{2}$ and $f=2 \mathrm{GHz}$ for low noise applications.

Using the same method, the optimized transistor sizes at any frequencies and any biases can be found. Table IV summarizes the frequency performance and noise performance of the optimal device sizes at $f=2,4,6 \mathrm{GHz}$ for LNA applications. For the device with $A_{E}=0.5 \times 20 \times 2 \mu \mathrm{m}^{2}$, even at $f=6 \mathrm{GHz}$ and $J_{C}=0.16 \mathrm{~mA} / \mu \mathrm{m}^{2}$, the noise figure is still $2.0 \mathrm{~dB}$ and the associate available gain can reach $14 \mathrm{~dB}$.

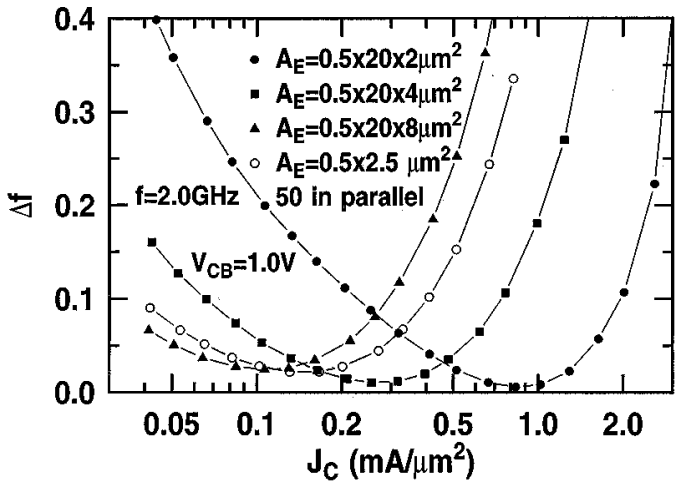

Fig. 14. $\Delta f$ versus collector current density for four different devices. $\Delta f$ is the difference between the minimum noise figure and the noise figure for $50 \Omega$ source impedance.

TABLE IV

High-Frequency Performance of the Optimal Devices at $f=2,4$, AND 6 GHZ FOR LNA APPLICATIONS

\begin{tabular}{cccc}
\hline & $\begin{array}{c}\text { SiGe HBT } \\
2 \mathrm{GHz}\end{array}$ & $\begin{array}{c}\text { SiGe HBT } \\
4 \mathrm{GHz}\end{array}$ & $\begin{array}{c}\text { SiGe HBT } \\
6 \mathrm{GHz}\end{array}$ \\
\hline $\mathrm{A}_{\mathrm{E}}=\mathrm{W} \times \mathrm{L} \times \mathrm{S}\left(\mu \mathrm{m}^{2}\right)$ & $0.5 \times 20 \times 6$ & $0.5 \times 20 \times 4$ & $0.5 \times 20 \times 2$ \\
$\mathrm{~J}_{\mathrm{C}}\left(\mathrm{mA} / \mu \mathrm{m}^{2}\right)$ & 0.1 & 0.13 & 0.16 \\
and $\mathrm{V}_{\mathrm{CB}}=1 \mathrm{~V}$ & & & \\
$\mathrm{f}_{\mathrm{T}}(\mathrm{GHz})$ & $\sim 22$ & 27 & 29.4 \\
$\mathrm{f}_{\max }(\mathrm{GHz})$ & $\sim 40$ & 44.3 & 47.8 \\
$\mathrm{NF}_{\min }(\mathrm{dB})$ & $\sim 0.95$ & 1.33 & 1.78 \\
$\mathrm{NF}_{50}(\mathrm{~dB})$ & $\sim 1.04$ & 1.49 & 2.01 \\
$\mathrm{R}_{\mathrm{n}}(\Omega)$ & $\sim 7$ & 9 & 17 \\
$\mathrm{G}_{\mathrm{A}, \mathrm{assoc}}(\mathrm{dB})$ & $\sim 19$ & 15.36 & 14 \\
\hline
\end{tabular}

\section{SUMMARY}

Geometrical scaling issues including width scaling, length scaling and stripe number scaling are investigated from an RF design perspective. Since the optimization of the size of the transistors in Si RF circuit designs is crucial, we use a method that can optimize the emitter geometry in order to minimize the matching circuit losses and overall noise figure. This method not only can choose a device, which can match $50 \Omega$ very well, it can also select a device with smaller minimum noise figure, which will improve the noise performance. In real LNA design (assuming $50 \Omega$ system), after choosing this optimized transistor, both base inductance and emitter inductance are also needed. In general, base inductance is mainly used to offset the imaginary part of $Z_{\text {opt }}$, while the emitter inductance is mainly designed to make the real part of the input impedance $\operatorname{Re}\left(Z_{\text {in }}\right)=$ $50 \Omega$ (assuming $50 \Omega$ system). If both base inductance and emitter inductance are more carefully designed, close to simultaneously noise matching and power matching can be realized. Using this method, we conclude that a SiGe HBT with emitter area $A_{E}=0.5 \times 20 \times 6 \mu \mathrm{m}^{2}$ is optimum device geometry for low noise applications at $J_{C}=0.1 \mathrm{~mA} / \mu \mathrm{m}^{2}$ and $2 \mathrm{GHz}$, while $A_{E}=0.5 \times 20 \times 4 \mu \mathrm{m}^{2}$ and $A_{E}=0.5 \times 20 \times 2 \mu \mathrm{m}^{2}$ are the optimal device sizes at $4 \mathrm{GHz}$ and $6 \mathrm{GHz}$, respectively. 


\section{ACKNOWLEDGMENT}

The wafers were fabricated at IBM Microelectronics, Essex Junction, VT. The authors would like to thank D. Ahlgren and B. Meyerson for their contributions to this work.

\section{REFERENCES}

[1] D. Ahlgren, M. Gilbert, D. Greenberg, S.-J. Jeng, J. Malinowski, D. Nguyen-Ngoc, K. Schonenberg, K. Stein, D. Sunderland, R. Groves, K. Walter, G. Hueckel, D. Colavito, G. Freeman, D. Harame, and B. Meyerson, "Manufacturability demontration of an integrated SiGe HBT technology for the analog and wireless marketplace," in IEDM Tech. Dig., 1996, pp. 859-862.

[2] S. P. Voinigescu, M. C. Maliepaard, J. L. Showell, G. E. Babcock, D. Marchesan, M. Schroter, P. Schvan, and D. L. Harame, "A scalable highfrequency noise model for bipolar transistors with application to optimal transistor sizing for low-noise amplifier design," IEEE J. Solid-State Circuits, vol. 32, pp. 1430-1438, Sept. 1997.

[3] G. Niu, W. E. Ansley, S. Zhang, J. D. Cressler, C. S. Webster, and R. Groves, "Noise parameter optimization of UHV/CVD SiGe HBT's for RF and microwave applications," IEEE Trans. Electron Devices, vol. 46, pp. 1589-1598, Aug. 1999

[4] H. A. Haus and R. B. Adler, Circuit Theory of Linear Noisy Networks. New York: Wiley, 1959.

[5] G. Niu, S. Zhang, J. D. Cressler, A. J. Joseph, J. S. Fairbanks, L. E. Larson, C. S. Webster, W. E. Ansley, and D. L. Harame, "Noise parameter modeling and SiGe profile design tradeoffs for RF applications," in Proc. 2000 IEEE Topical Meeting on Silicon Monolithic Integrated Circuits in RF Systems, 2000, pp. 9-14.

[6] H. Schumacher, U. Erben, and W. Dürr, "SiGe HBT-the noise perspective," Solid-State Electron., vol. 41, no. 10, pp. 1485-1492, 1997.

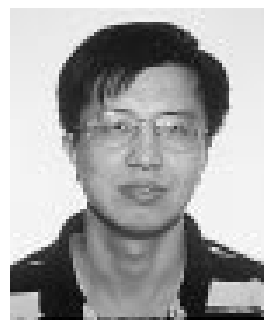

Shiming Zhang (S'99) received the B.E. degree in electrical engineering from the Beijing Polytechnic University (BPU), Beijing, China, in 1992, and the M.S. degree in electrical and computer engineering from Auburn University, Auburn, AL, in 1999, where he is currently pursuing the Ph.D. degree in electrical and computer engineering.

From September 1992 to August 1997, he worked on SiGe HBT at BPU as a Research Assistant. His research interests at BPU included layout, profile design, dc and low temperature characterization, and fabrication processing of SiGe HBTs. His main research interests include microwave characterization and modeling of SiGe HBTs and circuits and radiation effects study of SiGe HBTs, GaAs HBTs and SiGe:C HBTs. He has authored and co-authored more than 20 technical papers related to his research.

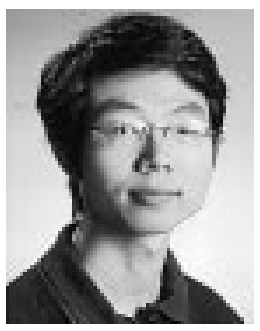

Guofu Niu (M'98) was born in Henan, China, in December 1971. He received the B.S., M.S., and Ph.D. degrees in electrical engineering from the Fudan University, China, in 1992, 1994, and 1997, respectively.

From December 1995 to January 1997, he was a Research Assistant with the City University of Hong Kong, Hong Kong, and worked on the mixed-level device/circuit simulation and quantum effect programmable logic gates. From May 1997 to May 2000, he conducted postdoctoral research that focused on SiGe RF devices at Auburn University, Auburn, AL. He joined the faculty of Auburn University in June 2000, where he is currently Associate Professor of Electrical and Computer Engineering. His research interests include SiGe devices and circuits, noise, radiation effects, $\mathrm{SiC}$ devices, low temperature electronics, and TCAD. He has published more than 30 journal papers and more than 20 conference papers related to his research.

Dr. Niu served on the Program Committee of the Asia-South-Pacific Design Automation Conference (ASP-DAC) in 1997 and served as a Technical Reviewer for IEEE EleCtron DEvice LeTters, IEEE TRANSACTIONS ON Electron Devices, IEEE Journal of Solid-State Circuits, and IEEE MicrowaVe AND GUIDED WAVE LETTERS. He was listed in Who's Who in America and is a Program Committee Member of the Bipolar/BiCMOS Circuits and Technology Metting (BCTM).
John D. Cressler (F'01) received the B.S. degree in physics from the Georgia Institute of Technology, Atlanta, in 1984, and the Ph.D. degree in applied physics from Columbia University, New York, in 1990.

From 1984 to 1992, he was a Member of Research Staff, IBM Research Division, Thomas J. Watson Research Center, Yorktown Heights, NY, working on high-speed $\mathrm{Si}$ and $\mathrm{SiGe}$ bipolar technology. In addition to his responsibilities while at IBM, he was an Adjunct Professor of mathematics at Western Connecticut State University, Danbury, from 1987 to 1990, as well as an Adjunct Assistant Professor of electrical engineering at Columbia University from 1990 to 1992. In 1992, he left the IBM Research Division to join the Faculty of Auburn University, Auburn, AL. He is currently Philpott-Westpoint Stevens Professor of Electrical and Computer Engineering and Director of the Alabama Microelectronics Science and Technology Center (AMSTC), a multidisciplinary statefunded research center. His research interests include SiGe HBTs and FETs, $\mathrm{SiC}$ devices and technology, radiation effects, cryogenic electronics, Si-based $\mathrm{RF} /$ microwave circuits, reliability physics, noise, linearity, device simulation, and compact circuit modeling. He has published over 230 technical papers related to his research, written four book chapters, received five awards from the IBM Research Division, and holds one U.S. patent. He has served as a Consultant to IBM, Analog Devices, Westinghouse, ITRI/ERSO (Taiwan), Teltech, the National Technological University, Commercial Data Servers, MemsOptical, Texas Instruments, Houston, and On Semiconductor.

Dr. Cressler has served on the Technical Program Committees of the International Solid-State Circuits Conference (1992-1998 and 1999-2001), the Bipolar/BiCMOS Circuits and Technology Meeting (1995-1999), the International Electron Devices Meeting (1996-1997), the IEEE Topical Meeting on Silicon Monolithic Integrated Circuits in RF Systems (1998-present) and the IEEE Nuclear and Space Radiation Effects Conference (1999-2000). He was the Technical Program Chairman of the 1998 ISSCC. He was associate editor of the IEEE JOURNAL OF SOLID-STATE CIRCUITS (1998-2001). He was appointed an IEEE Electron Devices Society Distinguished Lecturer in 1994, was awarded an IEEE Third Millennium Medal in 2000, the 1996 C. Holmes MacDonald National Outstanding Teacher Award by Eta Kappa Nu, the 1996 Auburn University Alumni Engineering Council Research Award, the 1998 Auburn University Birdsong Merit Teaching Award, the 1999 Auburn University Alumni Undergraduate Teaching Excellence Award, and the 1994 Office of Naval Research Young Investigator Award for his SiGe research program.

Alvin J. Joseph (M'96) received the B.E. degree in electrical engineering from Bangalore University, Bangalore, India, in 1989, and the M.S. and Ph.D. degrees in electrical engineering from Auburn University, Auburn, AL, in 1992 and 1997, respectively. His doctoral research involved the study of physics and optimization and modeling of cryogenically operated SiGe HBTs.

In 1997, he joined the SiGe Technology Development Group, IBM Microelectronics Division, Essex Junction, VT. He has been involved in various aspects of installing several SiGe BiCMOS technologies into production. He is currently the Process Integration Team Leader for qualifying the $0.18 \mu \mathrm{m} \mathrm{SiGe}$ BiCMOS technology to production. He has authored and co-authored several technical journal papers and conference publications related to SiGe HBTs.

Gregory Freeman (S'86-M'90) received the B.S.E.E. degree from the University of Delaware, Newark, in 1984, and the M.S.E.E. and Ph.D. degrees from Stanford University, Stanford, CA, in 1986 and 1991, respectively. His dissertation related to novel approaches for development and control of manufacturing processes.

He joined IBM in 1991 and has ten years of experience in the field of semiconductor device research and development. Since 1994, he has been involved in various forms in the research and development of SiGe HBT BiCMOS technology for wireless and wired networking applications, including early technology development and qualification. His recent achievements include leading a team to develop the world's first $210 \mathrm{GHz}$ silicon-germanium heterojunction transistor. Since 2000, he has been a Senior Engineering Manager, IBM Microelectronics, Hopewell Junction, NY, responsible for communications technology research and development including device design and circuit applications and process integration for SiGe HBTs as well as RF-CMOS. He has authored over 20 technical publications and presentations in the fields of electrical characterization and SiGe HBT BiCMOS technology. 
David L. Harame (S'77-M'83-SM'01) was born in Pocatello, ID, in 1948. He received the B.A. degree in zoology from the University of California, Berkeley, in 1971, the M.S. degree in zoology from Duke University, Durham, NC, in 1973, the M.S. degree in electrical engineering from San Jose State University, San Jose, CA, in 1976, and the M.S. degree in materials science and the Ph.D. in electrical engineering from Stanford University, Stanford, CA, in 1984.

He joined IBM's Bipolar Technology Group, IBM T. J. Waston Research Center, Yorktown Heights, NY, in 1984, where he worked on the fabrication and modeling of silicon-based integrated circuits. His specific research interests there included silicon and SiGe-channel FET transistors, NPNand PNP SiGe-based bipolar transistors, complementary bipolar technology, and BiCMOS technology for digital and analog and mixed-signal applications. In 1993, he joined IBM's Semiconductor Research and Development Center, Advanced Semiconductor Technology Center (ASTC), Hopewell Junction, NY, where he was responsible for the development of SiGe technology for mixed signal applications. He managed SiGe BiCMOS technology development at the ASTC through 1997. In 1998, he joined IBM's Manufacturing Organization, Essex Junction, VT, where he managed a SiGe group and installed the $0.5 \mu \mathrm{m}$ SiGe BiCMOS process in the manufacturing line. In 1999, he rejoined the Semiconductor Research Corporation while remaining in Essex Junction, VT

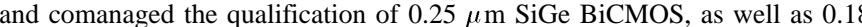
$\mu \mathrm{m}$ SiGe BiCMOS and two derivative SiGe BiCMOS technologies. In May 2000, he became the Senior Manager of the RF Analog Modeling and Design Kit Department.

Dr. Harame is a Distinguished Engineer of the IBM Corporation, an Executive Committee member of the Bipolar/BiCMOS Circuits and Technology Meeting (BCTM), and a member of the Compact Modeling Council. 